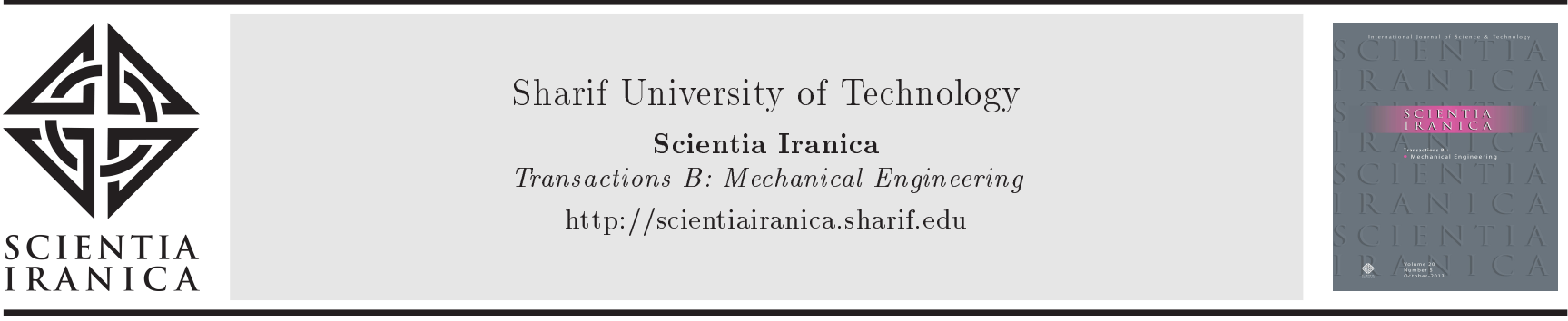

Research Note

\title{
Impact analysis of thick cylindrical sandwich panels with foam core subjected to single and multi-mass impacts
}

\author{
S. Patil ${ }^{\mathrm{a}}$ and D.M. Reddy* \\ School of Mechanical Engineering, Vellore Institute of Technology, Vellore-632014, India.
}

Received 27 April 2020; received in revised form 17 September 2020; accepted 9 November 2020

\author{
KEYWORDS \\ Sandwich panel; \\ ABAQUS/CAE; \\ Low-velocity impact; \\ Impact damage; \\ Multi-mass impact.
}

\begin{abstract}
This paper aims to study the impact analysis of a composite sandwich panel with a flexible foam core subjected to low-velocity impact loading using a finite element model in ABAQUS/CAE software. Impact damage remains a major concern for all structural components; creating internal damage and reducing the structural strength of a structure. Very few multiple-mass impact studies have been done on the composite sandwich panel. In the present work, the formulation is based on the first-order shear deformation theory which is used to develop the model. Impacts were done over the top of the face sheet with different velocities and impact masses. The numerical model is verified by that of the experimental literature. Good agreements in terms of contact-force histories and deformation of the sandwich panel are found. Once results are validated for a single impact, furthermore, the study has been extended to multi-mass impact analysis with varying velocities of the impactor. Comparisons of various parameters such as contact force, deformation, and von Mises stress results are reported. Also, comparisons of impact responses shown for a cylindrical sandwich panel with a flexible core were studied and reported.
\end{abstract}

(C) 2021 Sharif University of Technology. All rights reserved.

\section{Introduction}

Composites materials are important to engineering applications. Composites are lightweight and have high structural strength and stiffness. Because of these qualities, they are the optimum solution to material problems being faced in the engineering world today and, hence, are used in many industries such as aerospace and marine industries. During the use

\footnotetext{
*. Corresponding author.

E-mail address: dmreddy@vit.ac.in (D.M. Reddy)
}

doi: $10.24200 /$ sci. 2020.55341 .4180 of parts manufactured using composites, many faced impacts from small objects like rocks and birds, which can lead to impact damage in the composite, thus reducing the overall structural strength of the part. Here, low-velocity impacts causing damage of composite materials were studied considering parameters like energy and velocity, and it was concluded that damage can be internal and external. The use of composite sandwich panels is increasing in industries such as aerospace, marine, automotive, and military industries because of their high strength, elasticity, corrosionresistance, manufacturability, and stability. However, the problem with composite materials is that they have low impact damage resistance as measured by 
the low fracture toughness in the laminated composite face sheets. Because of the laminar structure of the composite material, it is hard to measure the impact damage on the panel decreasing the load bearing capacity of the material. Therefore, there is a need to recognize, predict and avoid damage to composite materials.

Impacts are divided into high and low velocity. There is not a reasonable transition amongst categories and authors have given different definitions based on the amount of energy transferred between the two objects $[1,2]$. Low-velocity impact is very dangerous and invisible to the naked eye. Olsson [3] proposed a new method to predict the impact response and damage in composite cylinder structures. Krishnamurthy et al. [4] concluded that the reasons for the damage created in a sandwich structure under impact are due to cracking, delamination. He et al. [5] performed both experimental and numerical studies on a hybrid sandwich structure and evaluated the damaging effect for the range of impact energies. Long et al. [6] investigated the failure of a sandwich plate made of faceplates and a foam core under impact. In order to find details of the structural failure, they were tested under an ultrasonic microscope. Hosseini et al. [7] proposed a new analytical method to study the dynamic response of a laminated composite cylindrical shell under impact using ABAQUS/CAE software. Khalil et al. [8] developed the spring-mass model using the higher-order analysis theory to determine the failure. The new two degrees of freedom spring model was used by Davar [9] to investigate the contactforce history. Kumar and Patil [10,11] modeled the composite plate using ABAQUS, in order to study the parameters under low impact velocity with different stack orientation for the plate structure. Fard et al. [12] used an improved higher-order sandwich panel theory for composite sandwich material with cores, under the low impact of small and large impactor masses. Analytically obtained results were compared with Finite Element (FE) model ABAQUS/CAE results. To study the dynamic response of the sandwich structure, researchers have conducted many numerical and experimental studies on sandwich cylindrical panels. [13-17].

Vignjevic et al. [18] investigated the soft body impact performance on composite sandwich panels with a corrugated core. The panels with a corrugated core exhibit good impact resistance to the face sheet. Wang et al. [19] addressed the problem associated with uniform and graded foam cores. The numerical model was validated by comparing the simulation and experimental results in terms of the deformation of the face sheets. Zhang et al. [20] investigated low velocity impact on asymmetric sandwich beams. They concluded that the sandwich beams with asymmetric factor $\alpha>1$ have a larger energy absorption than those with asymmetric factor $0<\alpha<1$. Zhang et al. [21] studied the dynamic response of slender multilayer sandwich beams with metal foam cores subjected to low-velocity impact. Using analytical formulae, optimal design charts are constructed to minimize the mass of multilayer sandwich beams for a given low-velocity impact resistance. Pourmoayed et al. [22], Khanjani et al. [23] studied parameters such as thickness, radius of curvature and sector angle on the static and dynamic response of composite cylindrical sandwich panels. They have been investigated using a Higher-order Sandwich Panel Theory (HSAPT) on thick-laminated-faced cylindrical sandwich panels with a transversely flexible core.

Mikhasev et al. [24] investigated the assessment of dynamic characteristics on the equivalent single-layer linear theory for laminated shells, and free and forced vibrations of thin cylindrical sandwich panels. Fard et al. [25], conducted free vibration and buckling analyses of cylindrical sandwich panels using an improved higher order sandwich panel theory. Yahaya et al. [26] studied the effects of the core in minimizing the back-face deflection of sandwich panels upon impact by foam projectiles. Khalili et al. [27] modelled cylindrical composite sandwich shells subjected to low velocity impact considering a transversely compliant core. Zhou et al. [28] investigated the perforation resistance of sandwich structures using experimental study. Joladarashi et al. [29,30] studied a comparative analysis on a composite sandwich structure under both normal and oblique impact loading. Chen et al. [31] investigated the response of aluminum foam core sandwich panels to localized air blasts and optimized a mass allocation strategy for performance.

Based on the literature study, it was observed that very few studies have been performed on cylindrical sandwich panels with a foam core, considering multimass impact under low-velocity conditions. The firstorder shear deformation theory is used to develop the model. An attempt has been made in this work to address the responses of composite sandwich panels. The present FE model is validated into a literature model for single mass impact considering the behavior between the face-sheet and the foam core. After validation of the model with references, the behavior of the sandwich model under multi-mass impact is simulated. Comparison of various parameters, such as contact force, deformation, and von Mises stress results, are reported and discussed.

\section{Modeling and formulation}

\subsection{Mathematical modeling}

The cylinder composite sandwich panel is made with two face-sheets with radius $(R)$ and length $(L)$, as shown in Figure 1. In the face, sheets are separated 


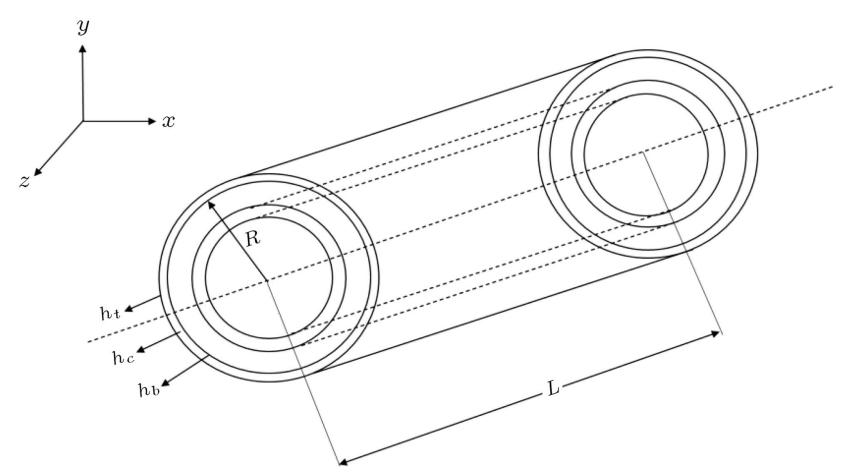

Figure 1. Cylinder composite sandwich panel with coordinates.

by the top and bottom face sheets of the panel and indicated by top $(t)$ and bottom $(b)$, respectively. In the analysis, the assumptions were made particular to small deformation structures.

Based on the classical first order shear deformation theory, the axial, tangential, and radial displacement components are denoted by $u, v$, and $w$, respectively. Here, $u, v$, and $w$ are the displacements, and expressed in Eq. (1):

$$
\begin{aligned}
& u_{i}(x, z, \theta, t)=u_{0}^{t}(x, \theta, t)+z_{t} \Psi_{x}^{i}(x, \theta, t), \\
& v_{i}(x, z, \theta, t)=v_{0}^{t}(x, \theta, t)+z_{t} \Psi_{x}^{i}(x, \theta, t), \\
& w_{i}(x, z, \theta, t)=w_{0}^{t}(x, \theta, t) .
\end{aligned}
$$

Along the $x$ and $y$ axis, the rotational components are presented and denoted as $\Psi_{x i}$ and $\Psi_{y i}$. Displacements along $x$ and $y$ for top and bottom sheets are denoted by $u_{i}$ and $v_{i}$, for vertical coordinates are is denoted by $Z_{i}(i=t, b)$, and strains of the face-sheets are given as in $\mathrm{Eq} .(2)$ :

$$
\begin{aligned}
& \epsilon_{x x}^{i}=\epsilon_{0 x x}^{i}+z_{i} k_{x x}^{i}, \epsilon_{\theta \theta}^{i}=\epsilon_{0 \theta \theta}^{i}+z_{i} k_{\theta \theta}^{i}, \epsilon_{z z}^{i}=0, \\
& \gamma_{x \theta}^{i}=2 \epsilon_{x \theta}^{i}=\epsilon_{0 x \theta}^{i}+z_{i} k_{x \theta}^{i}, i=t, \\
& \gamma_{x z}^{i}=2 \epsilon_{x z}^{i}=\epsilon_{0 x z}^{i}, \gamma_{\theta z}^{i}=2 \epsilon_{\theta z}^{i}=\epsilon_{0 \theta z}^{i} .
\end{aligned}
$$

In plane displacements of the core in $x$ and $y$ axis is given by $u_{k}^{c} v_{k}^{c}$, and for vertical is given by $w_{k}^{c}$ $(k=1,2,3)$. Radius of curvature for face sheet is given by $R_{c}$. The boundary conditions and governing equation is derived from the Hamilton's principle and it is minimization of Lagrangian equation given by Eq. (3):

$$
\int_{0}^{T} \delta L d t=\int_{0}^{T}\left[\delta K-\delta U+\delta W_{e x t}\right] d t=0
$$

where $\delta K, \delta U$, and $\delta W$ are variation of the kinetic energy, strain energy and potential energies respectively due to the applied loads and boundary condition applied for cylindrical sandwich.

\subsection{Impact force model}

The impactor with masses M1, M2 and velocities V1, V2 and respectively strikes $N$ times on a cylindrical composite panel at coordinates $\left(x_{1}, y_{1}\right),\left(x_{2}, y_{2}\right)$ and $\left(x_{3}, y_{3}\right)$ as shown in the Figure $2(\mathrm{a})$ and (b). The equation of motion thus obtained and assumes the contact load $q_{j}(j=t, b)$ and expression is given by Eq. (4):

$$
q_{t}(x, \theta, t)=\sum_{m=1}^{\infty} \sum_{n=0}^{\infty}\left[\sum_{i=1}^{N} q_{m n(t)}^{i}\right] \sin \left(\alpha_{m} x\right) \cos (n \theta)
$$

The contact load $F_{i}$, at point $\left(x_{i}, y_{i}\right)$ on the top face sheets, then Fourier coefficients $q_{m n i}$ is given by Eq. (5):

$$
\begin{aligned}
& q_{m o}^{i}(t)=\frac{F_{c}^{i}(t)}{\pi L R} \sin \left(\alpha_{m} x_{i}\right) \quad \text { if } \quad n=0, \\
& q_{m n}^{i}(t)=\frac{2 F_{c}^{i}(t)}{\pi L R} \sin \left(\alpha_{m} x_{i}\right) \cos \left(n \theta_{i}\right) \quad \text { if } \quad n>0 .
\end{aligned}
$$

The length of the cylinder panel is given as $L$, the impact is denoted by $i$, and the impact contact force as $F(t)$ for the spring-mass model with two degrees of freedom. Regarding Figure 3 the load is applied to variable areas and the corresponding center of this area can be anywhere on the top face sheet, as given in Eq. (6):

$$
x_{i 2}-x_{i 1}=2 l_{2}^{i} \quad \text { and } \quad R\left(\psi_{i 2}-\psi_{i 1}\right)=2 l_{1}^{i},
$$
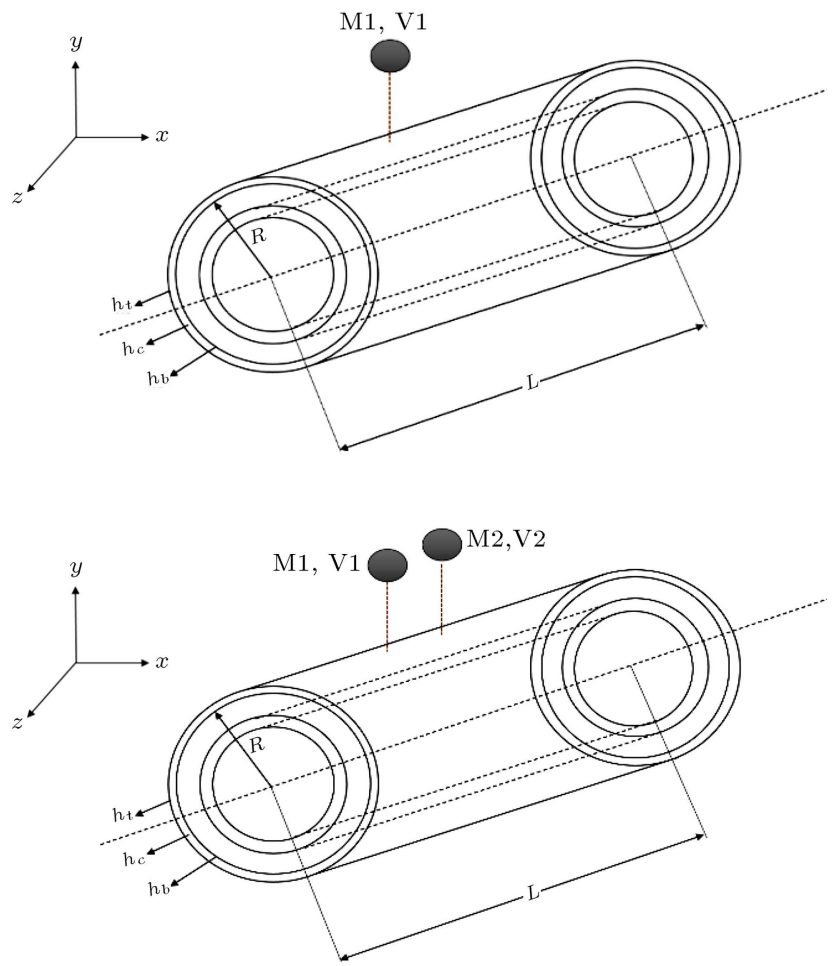

Figure 2. (a) Single-mass impact force model, and (b) multi-mass impact force model. 


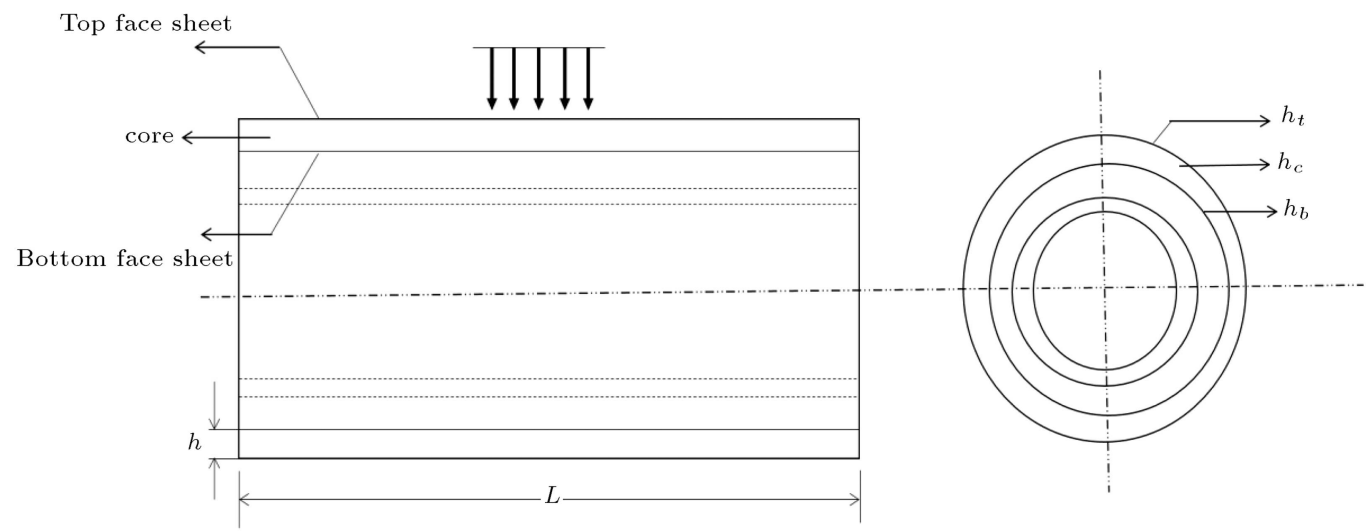

Figure 3. Front and side view of impact force model

$$
x_{i L}=\frac{x_{i 2}+x_{i 1}}{2} \text { and } \quad \varphi_{i L}=\frac{\psi_{i 2}+\psi_{i 1}}{2} .
$$

Here, $x_{i L}$ and $\varphi_{i L}$ are the coordinates of the centre point of the area of the applied load.

In the analysis, the spherical impactor is in contact with the surface of the cylinder model. To calculate the contact applied force, $F_{i}$ is given by the Timoshenko and Goodier equation. The impactor radius $R_{i}$ is given in Eq. (7):

$$
R_{\text {contact }}^{i}(t)=0.909\left(\frac{F_{c}^{i}(t) \cdot R^{i}}{E}\right)^{\frac{1}{3}} .
$$

\section{Finite element modeling}

In this present work, Abaqus/CAE software is used to model the cylindrical composite panel. In the model, the impactor was considered as rigid and contactconstraints are also considered between the surface and the impactor. The composite sandwich panel is made up of a top- face sheet, a bottom-face sheet, and a core. The analysis is performed in ABAQUS/CAE, where the face sheet and core are modeled by SC8R elements. The dimensions for the parts of the cylinder are given in Table 1. Mechanical properties are given for parts of the cylinder, including the face-sheet with a core. Impactor properties, including geometric properties, are given in Tables 2 and 3 [32].

The auto mesh is selected to mesh all the cylinder

Table 1. Dimension for cylinder parts.

\begin{tabular}{lc}
\hline Dimension & Value $(\mathbf{m m})$ \\
\hline Outer diameter & 1500 \\
Inner diameter & 1350 \\
Length of cylinder & 3000 \\
Thickness of foam core & 132 \\
Thickness of top face-sheet & 9 \\
Thickness of bottom face-sheet & 9 \\
\hline
\end{tabular}

Table 2. Dimension for the impactor.

\begin{tabular}{lc}
\hline Dimension & Value \\
\hline Radius $(\mathrm{mm})$ & 25 \\
Mass $(\mathrm{g})$ & 10 \\
Young's modulus, E (GPa) & 25 \\
Velocity $(\mathrm{m} / \mathrm{s})$ & $1,3,5,7$, and 9 \\
Poisson ratio, $v$ & 0.3 \\
Density $\left(\mathrm{kg} / \mathrm{m}^{3}\right)$ & 7960 \\
\hline
\end{tabular}

Table 3. Properties considered for different parts of the cylinder.

\begin{tabular}{ccc}
\hline Property & Face-sheet & Foam-core \\
\hline$E_{11}(\mathrm{GPa})$ & 131 & 0.007 \\
$E_{22}(\mathrm{GPa})$ & 10.33 & 0.007 \\
$E_{33}(\mathrm{GPa})$ & 10.33 & 0.007 \\
$G_{12}(\mathrm{GPa})$ & 6.9 & 0.0035 \\
$G_{13}(\mathrm{GPa})$ & 6.9 & 0.0035 \\
$G_{23}(\mathrm{GPa})$ & 6.2 & 0.0035 \\
$v_{12}$ & 0.2 & 0.0001 \\
$v_{13}$ & 0.5 & 0.0001 \\
$v_{23}$ & 0.5 & 0.0001 \\
\hline$C_{y} l i n d r i c a l$
\end{tabular}

Cylindrical geometrical properties are given by layup laminates $[0 / 90 / 0 /$ core $/ 0 / 90 / 0]$ :

$R_{c}=10 \mathrm{~h}, L=2 \mathrm{Rc}, h_{t}=h_{b}=3 \mathrm{~mm}, h_{c} / h=0.88$.

parts with the impactor. For the mesh, Quad/Tria elements are used and shown in Figure 4. The cylindrical panel is made up of the core and two face sheets. In this study, single mass and multi-mass impacts are carried out to understand the behavior of the sandwich panel. The single and multiple impact models are shown in Figure 5.

\section{Validation of results and discussion}

The validation of the developed numerical model is 


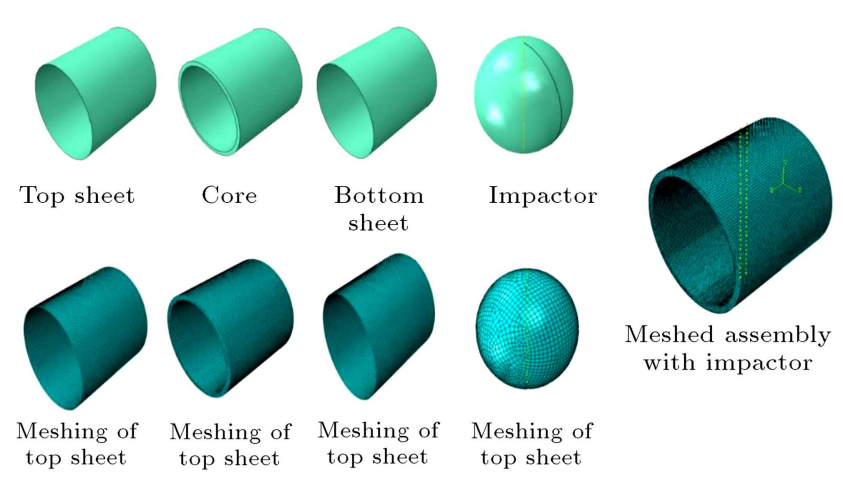

Figure 4. Complete mesh of the cylindrical sandwich panels with foam core and impactor.

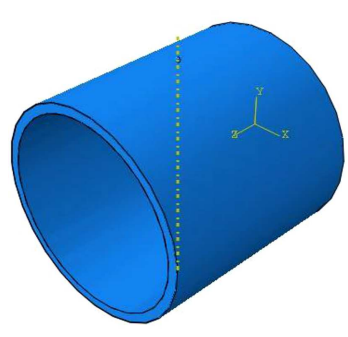

(a)

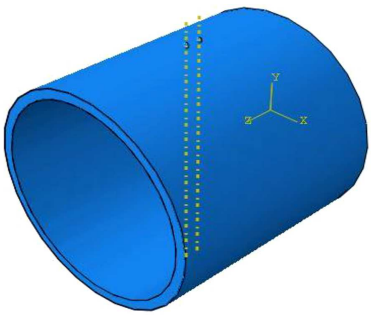

(b)
Figure 5. Cylindrical sandwich panels with single and multi-mass impactor loading condition at the center of the cylinder surface.

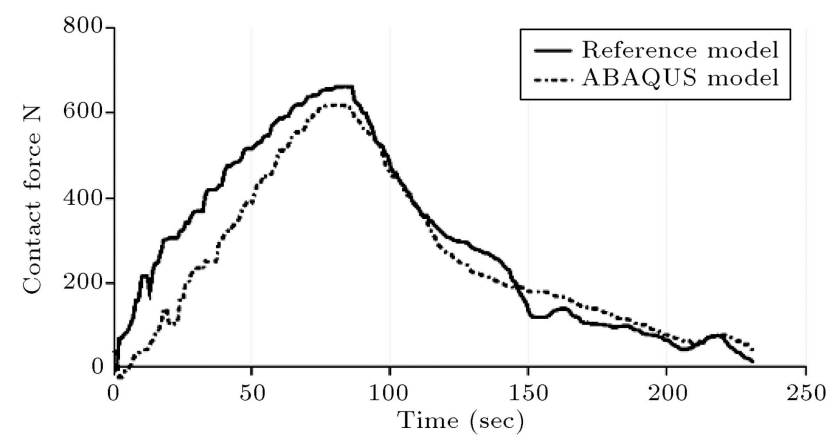

Figure 6. Contact force vs time history comparing with reference model with ABAQUS model subjected to single impactor [32].

demonstrated by comparing the results in terms of contact force and deformation of the sandwich cylinder panel, with impact time obtained from simulation, with experimental results available in literature [43]. Figures 6 and 7 represent contact force histories and deflection for ABAQUS and the reference model subjected to single impact. The history of contact force obtained from the ABAQUS model has good agreement with the reference model, but there is a small variation between the results from the two models, as indicated in Figure 7. The comparisons between the models show their accuracy.

To obtain the system responses in the impact region, the sandwich cylinder panel is meshed using

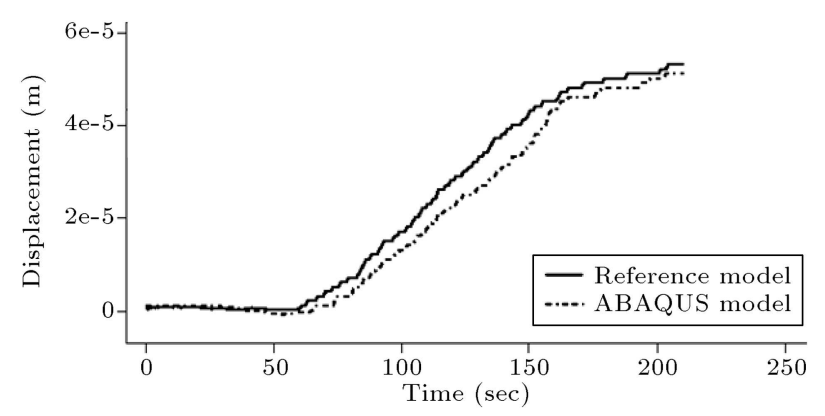

Figure 7. Displacement vs time histories comparing with reference model with cylindrical sandwich panel subjected to single impactor of impact velocity $3 \mathrm{~m} / \mathrm{s}$ [32].

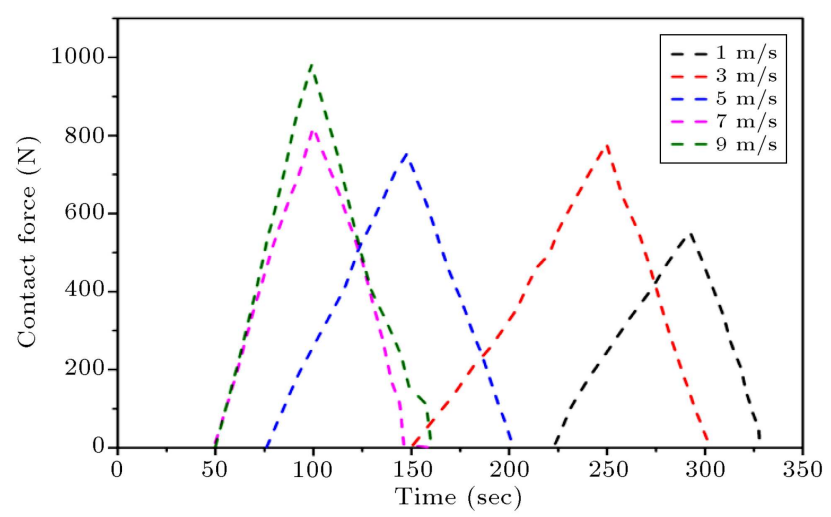

Figure 8. Contact force vs time plot for single impactor under different impact velocity.

SC8R and C3D8R elements for the face sheet and the core, respectively, as shown in Figure 4. The clearance between the surface of the top face-sheet and the surface of the impactor is considered to be near to zero. First, the cylindrical sandwich panel with simply supported boundary conditions subjected to a single impact at location $(X, \theta)=(L / 2,0)$ is studied. In Figures 6 and 7 , the converged contact force and deflection histories are presented, respectively.

\subsection{Parametric study}

In this study, the response of composite sandwich panels by varying impact energy under fixed boundary conditions is investigated. Low velocity depends on many factors of laminates, such as the velocity and mass of the impactor, the stacking sequence and boundary condition. The present work investigates the effect of parameters like displacement, impact force and von-Mises stress variations on a composite sandwich panel.

The results of a simulation for a single impact were studied and plots for contact force and displacement versus time were plotted and shown in Figures 8 and 9, respectively. Furthermore, analysis and of a thick cylinder sandwich composite structure is investigated and discussed for multi-mass impacts under different velocities of the impactor. As seen in 


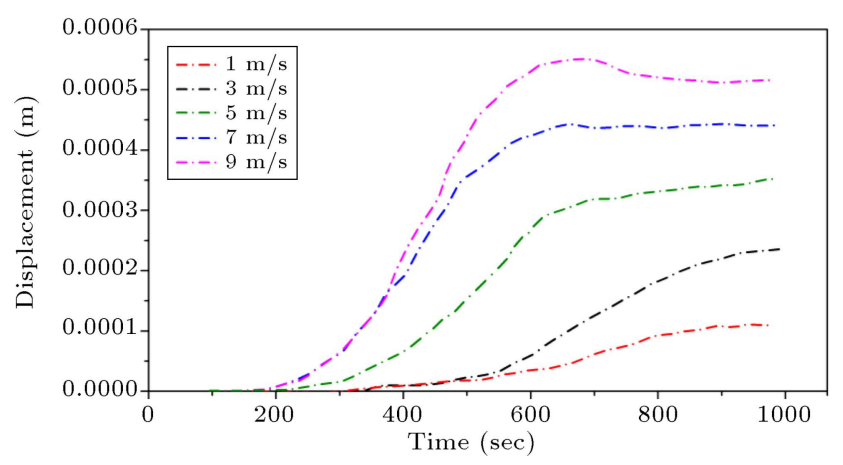

Figure 9. Displacement vs time plot for single-impactor under different impact velocity.

Figure 8, the contact force - time curve was obtained from a single impact with velocity $1 \mathrm{~m} / \mathrm{s}, 3 \mathrm{~m} / \mathrm{s}, 5 \mathrm{~m} / \mathrm{s}$, $7 \mathrm{~m} / \mathrm{s}$, and $9 \mathrm{~m} / \mathrm{s}$. Peak value is achieved at the time of single impact and then the value decreases momentarily when there is no contact between the cylinder and the impactor. Increasing the velocity of the impactor will get maximum impact force, and early contact on the surface on the center of the cylinder, as seen, and attains high contact force on the cylindrical panel impacted surface.

From Figure 9, in the case of displacement, the smooth curve indicates initially, before impact, that there is no displacement and at the time of contact there is a gradual increase in the displacement of the upper layer (top of the sheet). Then, when the impactor is tracing its path, the displacement again gains a constant value, as clearly indicated in the profile of the plot. The plot results are shown in Figure 9 and the analytical solutions, hence, validate the results. There was a slight variation in the maximum value pertaining to the type of boundary condition used and also the size of the impactor. After getting the same profile for a velocity of $1 \mathrm{~m} / \mathrm{s}$, more simulation was made for the different velocities of $3,5,7$, and $9 \mathrm{~m} / \mathrm{s}$ and their results were plotted. Increasing the velocity of the impactor will create more deformation on the surface at the center of the cylinder, as seen, and it will reach maximum by magnitude, as shown in Figure 9.

The dynamic response for a cylinder panel under a single impactor is investigated. The $3 \mathrm{D}$ counters of the von-Mises stress distribution of the sandwich panel and impactor under a simply supported boundary condition are represented in Figure 10. The von-Mises stress variation of a single impact on the top face of the sandwich composite panel is reported. As seen in Figure 11, unlike the single impact, the multi impact has two peaks. Each contact force indicates two impact peaks and then there is no peak as the impactor is retracting and there is no contact between the impactor and cylinder. When increasing the velocity of the impactor, it will get maximum impact peaks in contact force. From Figure 12, similar to a single impact,
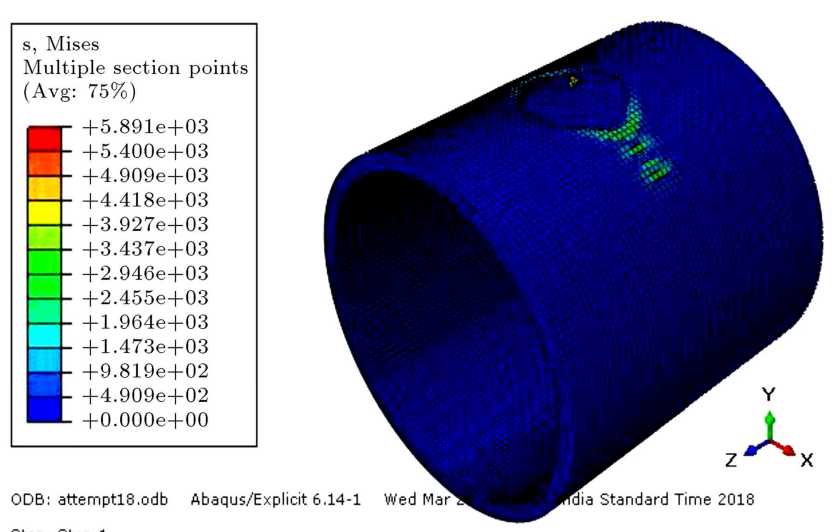

ODB: attempt1

Step: Step-1

Increment 99934: Step Time $=1000$.

Primary Var: S S M Mises
Deformed Var: $U$ Deformation Scale Factor: $+1.000 e+00$

Figure 10. 3D views for contact stress distribution on top of the sheet under single-impact at $3 \mathrm{~m} / \mathrm{s}$.

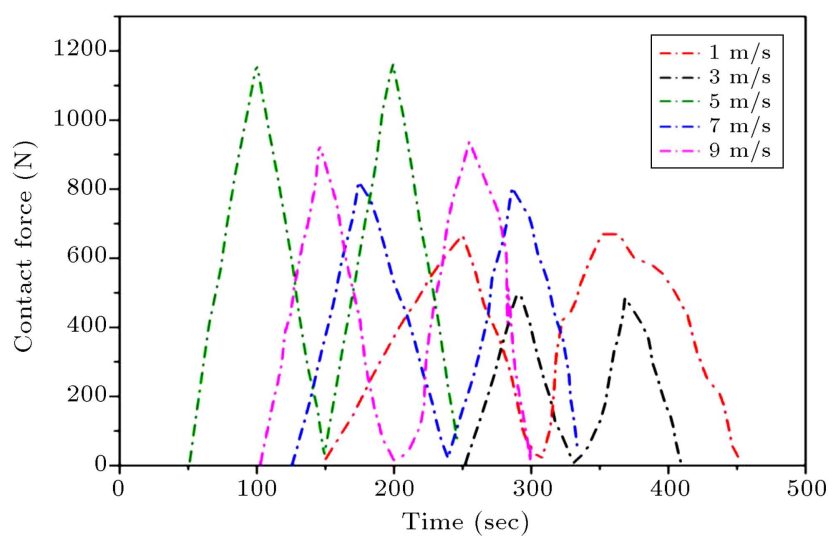

Figure 11. Contact force vs time plot for multi-impact impactor under different impact velocity.

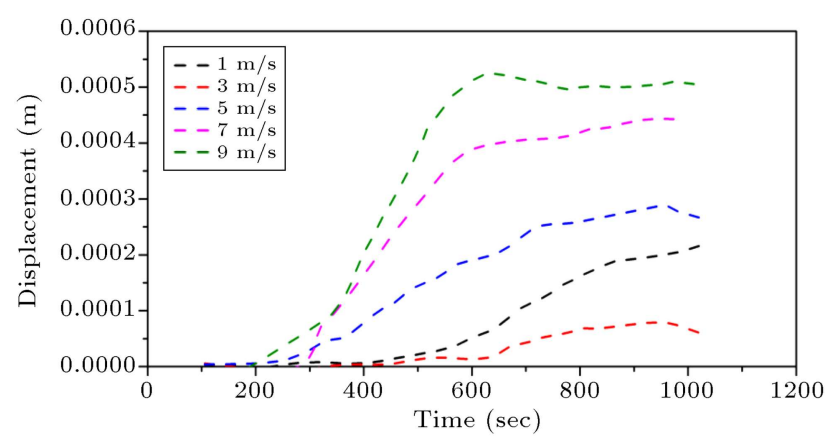

Figure 12. Displacement vs time plot for multi- impactor under different impact velocity.

the deflection curve is more or less same with a little deviation in the middle because of the propagating waves due to impact. To understand the response, further simulations for impact velocities of $3,5,7$, and $9 \mathrm{~m} / \mathrm{s}$ were performed and the results were studied. With the increase of impact velocity at the surface of the cylinder, deformation will increase.

The 3D counters of the von-Mises stress distribution of the sandwich panel and impactor under a 

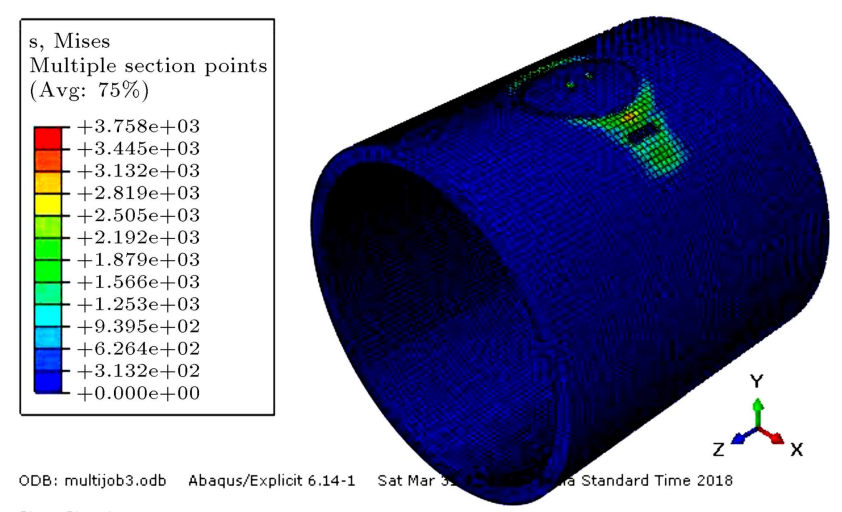

ODB: multijob3

Step: Step-1

99934: Step Time $=1000$

Primary Var: S, Mises
Deformed Var: U Deformation Scale Factor: $+1.000 e+00$

Figure 13. 3D views for contact stress distribution on top of the sheet under multi-impact at $3 \mathrm{~m} / \mathrm{s}$.

simply supported boundary condition are represented in Figure 13. The von-Mises stress variation of multimass impact on the top face of the sandwich composite panel is reported.

Composites are very crucial elements in the field of engineering and their use is increasing in the scientific world, but still there are certain limitations to their implementation. So, the main aim of this paper is to study the dynamic behavior of the sandwich composites under low impact velocity conditions. The composite was modeled using a cylinder and an impactor and simulations were performed where the impact was made at the centre of the cylinder with multi-mass impact. In order to understand the failure damages, impact analyses for sandwich composite panels under both single and multi-impacts are studied and discussed.

\section{Conclusion}

A numerical analysis is performed to investigate the low velocity impact response of a composite sandwich cylindrical panel with a flexible core under single and multi-mass impact. Analysis is carried out with finite element ABAQUS/CAE software. Numerical model results are verified by experimental literature models. Once results are validated for a single impact, further study was undertaken for multi impact by varying the velocities. The velocities of the impact varied as $1,3,5$, 7 , and $9 \mathrm{~m} / \mathrm{s}$. A numerical method can be used to study the resistance of similar structures. The results were plotted for contact- force history and displacements versus time, and their natures were analyzed. It was concluded that deformation of sandwich cylindrical panel laminate is increased by increasing the impactor velocity. It was also observed that the time required for impact decreased by increasing the impact velocity for all simulation results.

The focus was to evaluate the global deformation and contact force history for a sandwich panel. The amount of energy absorbed by the panel is different and it was observed that the core exhibits some deformation and the face sheet does not show significant damage. Upon increasing the impact energy, the top face-sheet fails and the sandwich core absorbs the remaining major energy. Increasing the velocity of the impactor will get maximum impact force and also obtain early contact on the surface at the center of the cylinder.

\section{Acknowledgement}

The project presented in this article was supported by the Science and Engineering Research Board (SERB) and the Department of Science and Technology (DST), Government of India (File Number: $\mathrm{ECR} / 2017 / 000512)$.

\section{References}

1. Cantwell, W.J. and Morton, J. "The impact resistance of composite materials-a review, Composites, 22(5), pp. 347-362 (1991).

2. Patil, S., Reddy, D.M., and Reddy, M. "Low velocity impact analysis on composite structures-A review", In A IP Conference Proceedings, 1, pp. 09, AIP Publishing (2018).

3. Olsson, R. "Analytical prediction of large mass impact damage in composite laminates", Composites Part A: Applied Science and Manufacturing, 32(9), pp. 12071215 (2001).

4. Krishnamurthy, K.S., Mahajan, P., and Mittal, R.K. "Impact response and damage in laminated composite cylindrical shell", Composite Structures, 59(1), pp.1536 (2003).

5. He, W., Liu, J., Wang, S., and Xie, D. "Low- velocity impact response and post-impact flexural behavior of composite sandwich structures with corrugated cores", Composite Structures, 189, pp. 37-53 (2018).

6. Long, S., Yao, X., Wang, H., and Zhang, X. "Failure analysis and modeling of foam sandwich laminates under impact loading", Composite Structures, 197, pp. 10-20 (2018).

7. Hosseini, M., Khalili, S.M.R., and Fard, K.M. "Indentation analysis of in-plane prestressed composite sandwich plates: an improved contact law", In Key Engineering Materials, 471, pp. 1159-1164 (2011).

8. Khalili, S.M.R., Rahmani, O., Malekzadeh Fard, K., and Thomsen, O.T. "High-order modeling of circular cylindrical composite sandwich shells with a transversely compliant core subjected to low velocity impact", Mechanics of Advanced Materials and Structures, 21(8), pp. 680-695 (2014).

9. Davar, A., Khalili, S.M.R., and Fard, K.M. "Assessment of different higher order theories for low-velocity impact analysis of fibre-metal laminate cylindrical shells", Proceedings of the Institution of Mechanical 
Engineers, Part L: Journal of Materials: Design and Applications, 228(3), pp. 160-189 (2014).

10. Kumar, K.S., Patil, S., and Reddy, D.M., "Modeling and analysis of low velocity impact on composite plate with different ply orientations", In International Conference on Innovation, Engineering and Entrepreneurship, pp. 515-521, Springer, Cham (2018).

11. Patil, S. and Mallikarjuna Reddy, D. "Study of oblique low velocity impact on composite plate", Materials Today: Proceedings (2020). Doi: 10.1016/j.matpr.2020.03.125

12. Fard, K.M., Ghorghabad, A.V., Azarnia, A.H., and Ghasemi, F.A., "High order impact elastic analysis of circular thick cylindrical sandwich panels subjected to multi-mass impacts", Latin American Journal of Solids and Structures, 12(12), pp. 2281- 2310 (2015).

13. Zhang, J., Qin, Q., Xiang, C., and Wang, T.J. "Dynamic response of slender multilayer sandwich beams with metal foam cores subjected to low-velocity impact", Composite Structures, 153, pp. 614-623 (2016).

14. Qin, Q., Zheng, X., Zhang, J., Yuan, C., and Wang, T.J. "Dynamic response of square sandwich plates with a metal foam core subjected to low-velocity impact", Int. J. Impact Eng., 111, pp. 222-235 (2018).

15. Yang, J.S., Ma, L., Schroder, K.U., Chen, Y.L., Li, S., Wu, L.Z., and Schmidt, R. "Experimental and numerical study on the modal characteristics of hybrid carbon fiber composite foam filled corrugated sandwich cylindrical panels", Polymer Testing, 68, pp. 8-18 (2018).

16. Zhang, J., Liu, K., Ye, Y., and Qin, Q. "Low-velocity impact of rectangular multilayer sandwich plates", Thin-Walled Structures, 141, pp. 308-318 (2019).

17. Ramakrishnan, K.R., Guerard, S., Maheo, L., Shankar, K., and Viot, P. "A new method for the study of parabolic impact of foam-core sandwich panels", Composites Part B: Engineering, 167, pp. 717-727 (2019).

18. Vignjevic, R., Campbell, J., Hughes, K., Orłowski, M., Garcea, S., Withers, P., and Reed, J. "Soft body impact resistance of composite foam core sandwich panels with unidirectional corrugated and tubular reinforcements", International Journal of Impact Engineering, 132, p. 103320 (2019).

19. Wang, E., Li, Q., and Sun, G. "Computational analysis and optimization of sandwich panels with homogeneous and graded foam cores for blast resistance", Thin-Walled Structures, 147, p. 106494 (2020).

20. Zhang, J., Qin, Q., Xiang, C., Wang, Z., and Wang, T.J. "A theoretical study of low-velocity impact of geometrically asymmetric sandwich beams", International Journal of Impact Engineering, 96, pp. 35-49 (2016).
21. Zhang, J., Qin, Q., Xiang, C., and Wang, T.J. "Dynamic response of slender multilayer sandwich beams with metal foam cores subjected to low-velocity impact", Composite Structures, 153, pp. 614-623 (2016).

22. Pourmoayed, A.R., Fard, K.M., and Shahravi, M. "Vibration analysis of a cylindrical sandwich panel with flexible core using an improved higher-order theory", Latin American Journal of Solids and Structures, 14(4), pp. 714-742 (2017).

23. Khanjani, M., Shakeri, M., and Sedighi, M. "A parametric study on the stress analysis and transient response of thick-laminated-faced cylindrical sandwich panels with transversely flexible core", Aerospace Science and Technology, 48, pp. 1-20 (2016).

24. Mikhasev, G.I., Eremeyev, V.A., Wilde, K., and Maevskaya, S.S. "Assessment of dynamic characteristics of thin cylindrical sandwich panels with magnetorheological core", Journal of Intelligent Material Systems and Structures, 30(18-19), pp. 2748-2769 (2019).

25. Malekzadeh Fard, K., Gholami, M., Reshadi, F., and Livani, M. "Free vibration and buckling analyses of cylindrical sandwich panel with magneto rheological fluid layer", Journal of Sandwich Structures and Materials, 19(4), pp. 397-423 (2017).

26. Yahaya, M.A., Ruan, D., Lu, G., and Dargusch, M.S. "Response of aluminium honeycomb sandwich panels subjected to foam projectile impact-An experimental study", International Journal of Impact Engineering, 75, pp. 100-109 (2015).

27. Khalili, S.M.R., Rahmani, O., Malekzadeh Fard, K., and Thomsen, O.T. "High-order modeling of circular cylindrical composite sandwich shells with a transversely compliant core subjected to low velocity impact", Mechanics of Advanced Materials and Structures, 21(8), pp. 680-695 (2014).

28. Zhou, J., Hassan, M.Z., Guan, Z., and Cantwell, W.J. "The low velocity impact response of foam-based sandwich panels", Composites Science and Technology, 72(14), pp. 1781-1790 (2012).

29. Joladarashi, S. and Kulkarni, S.M. "Comparative study of damage behavior of synthetic and natural fiber-reinforced brittle composite and natural fiberreinforced flexible composite subjected to low-velocity impact", Scientia Iranica, 27(1), pp. 341-349 (2020).

30. Joladarashi, S. and Kulkarni, S.M. "Investigation on effect of using rubber as core material in sandwich composite plate subjected to low velocity normal and oblique impact loading", Scientia Iranica, 26(2), pp. 897-907(2019).

31. Chen, G., Zhang, P., Liu, J., Cheng, Y., and Wang, H. "Experimental and numerical analyses on the 
dynamic response of aluminum foam core sandwich panels subjected to localized air blast loading", Marine Structures, 65, pp. 343-361 (2019).

32. Fard, K.M., Ghorghabad, A.V., Azarnia, A.H., and Ghasemi, F.A. "High order impact elastic analysis of circular thick cylindrical sandwich panels subjected to multi-mass impacts", Latin American Journal of Solids and Structures, 12(12), pp. 2281-2310 (2015).

\section{Biographies}

Shreekant Patil received his BE degree in Mechanical Engineering and his MTech degree in Machine Design in 2014 and 2016, respectively, from Visvesvaraya Technological University, Belagavi, Karnataka, India. $\mathrm{He}$ is currently working as a Research Scholar at the School of Mechanical Engineering, Vellore Institute of Technology, Vellore, Tamilnadu, India. His research interests include composite materials and impact dynamics. He has published and presented many papers in international journals and conferences.

Dehalhal Mallikarjuna Reddy received his BE degree in Mechanical Engineering and his MTech in Maintenance Engineering in 2000 and 2003, respectively, from Gulbarga University, Karnataka and SJCE Mysore, Karnataka, India. He received his $\mathrm{PhD}$ degree from the Indian Institute of Technology Madras (IIT$\mathrm{M})$ in 2008. He is currently working as Associate Professor and Head of the Department of Design and Automation at the School of Mechanical Engineering, Vellore Institute of Technology, Vellore, Tamilnadu, India. His research interests include dynamic analysis, vibration control and composite materials. He has published and presented many papers in international journals and conferences. 